\title{
Perfil epidemiológico e prisional das detentas de um município do médio norte de Mato Grosso
}

\section{Epidemiological and prison profile of the detention of a municipality of the north of Mato Grosso}

\author{
Bianca Carvalho da Graça ${ }^{1}$, Michele de Melo Mariano ${ }^{1}$, Juliana Herrero da Silva², Vagner \\ Ferreira do Nascimento ${ }^{3}$, Thalise Yuri Hattori ${ }^{4}$, Ana Cláudia Pereira Terças-Trette ${ }^{5}$
}

\begin{abstract}
Resumo
Objetivou-se apresentar o perfil de mulheres privadas de liberdade em uma cadeia pública da região médio de Mato Grosso. Trata-se de uma pesquisa do tipo transversal, com abordagem quantitativa realizada em 2017. Foi realizada aplicação de formulário semiestruturado contendo perguntas abertas e fechadas com as 57 mulheres, sendo as mesmas entrevistadas individualmente; posteriormente os dados foram sistematizados em planilhas eletrônicas e analisados pelo SPSS versão 20.0. O perfil predominante foi de participantes autodeclaradas pardas $(73,7 \%)$, com faixa etária entre 18 e 31 anos $(56,2 \%)$, ensino fundamental incompleto $(56,2 \%)$, donas de casa $(38,6 \%)$, solteiras $(47,4 \%)$, com até 4 filhos $(82,5 \%)$, detidas pelo crime de tráfico de drogas $(54,4 \%)$ e com período de reclusão de até dois anos $(82,5 \%)$. O perfil aqui descrito reflete a relação entre a população com maior fragilidade socioeconômica, a inserção no crime através do parceiro e o tráfico de drogas como busca de renda. Neste sentido faz-se necessário a elaboração de políticas públicas intersetoriais que possibilitem a redução das desigualdades sociais, de gênero e a inserção das mulheres desde a infância em ambientes que potencializem sua qualidade de vida.
\end{abstract}

Palavras chave: Epidemiologia. Mulheres. Prisões.

\begin{abstract}
The objective of this study was to present the profile of women deprived of their liberty in a public chain in the middle region of Mato Grosso. This was a cross-sectional survey with a quantitative approach carried out in 2017. A semi-structured questionnaire containing open and closed questions was applied to 57 women with individual interviews, later the data systematized in electronic spreadsheets and analyzed by the SPSS version 20.0. The predominant profile self-reported by the participants was brown (73.7\%), aged between 18 and 31 (56.2\%), incomplete elementary school (56.2\%), housewives (38.6\%), (47.4\%), with up to 4 children (82.5\%), arrested for the crime of drug trafficking $(54.4 \%)$ and with imprisonment for up to two years $(82.5 \%)$. The profile described reflects the relationship between the population with greater socioeconomic fragility, insertion in crime through the partner and drug trafficking as a search for income. In this sense is necessary the elaboration of intersectional public policies that allow the reduction of social and gender inequalities and the insertion of women since their childhood in environments that enhance the quality of life.
\end{abstract}

Keywords: Epidemiology. Women. Prisons.

\footnotetext{
${ }^{1}$ Enfermeira pela Universidade do Estado de Mato Grosso, Tangará da Serra, Mato Grosso, Brasil. Departamento de Enfermagem da Universidade do Estado de Mato Grosso, Tangará da Serra, Mato Grosso, Brasil.

${ }^{2}$ Mestranda em Genética e Biologia Molecular pela Universidade Federal do Rio Grande do Sul, Porto Alegre, Rio Grande do Sul, Brasil. Secretaria Municipal de Saúde de Tangará da Serra, Tangrá da Serra, Mato Grosso, Brasil.

${ }^{3}$ Departamento de Enfermagem da Universidade do Estado de Mato Grosso, Tangará da Serra, Mato Grosso, Brasil.

${ }^{4}$ Mestrado em Ciências da Saúde pela Universidade Federal da Grande Dourados, Dourados, Mato Grosso do Sul, Brasil. Departamento de Enfermagem da Universidade do Estado de Mato Grosso, Tangará da Serra, Mato Grosso, Brasil.

${ }^{5}$ Doutorado em Medicina Tropical pela Fundação Oswaldo Cruz, Mato Grosso, Brasil. Departamento de Enfermagem da Universidade do Estado de Mato Grosso, Tangará da Serra, Mato Grosso, Brasil. E-mail: ana.claudia@unemat.br
} 


\section{Introdução}

O sistema penitenciário brasileiro é regido por meio da Lei de Execução Penal (LEP), n ${ }^{\circ} 7210$, de 11 de julho de $1984^{(1)}$, dentre os direitos das reeducandas é previsto melhores condições de vida dentro das penitenciárias, principalmente em relação à saúde das pessoas privadas da liberdade, situação essa que contradiz com o cenário atual, em que há falta de projetos de ressocialização, precariedade e insalubridade dos ambientes prisionais, tornandoos propensos à proliferação de microrganismos patogênicos, além da superlotação desses ambientes, que é cada vez mais frequente - no Brasil e em demais países, como Colômbia, Estados Unidos, América Latina e Caribe ${ }^{(1-3)}$ - e prejudicial, tanto em relação ao aspecto social quanto ao pessoal. ${ }^{(4)}$

Segundo o Departamento de Monitoramento e Fiscalização do Sistema Carcerário e do Sistema de Execução de Medidas Socioeducativas (DMF), através do Novo Diagnóstico de Pessoas Presas no Brasil, o país ocupa o terceiro lugar no ranking mundial de população carcerária (711.463 detentos), ficando atrás apenas dos Estados Unidos e da China. (5) Desse total, 37.380 são mulheres, representando um acréscimo populacional de 567,4\% entre 2000 e 2014, superando o aumento da população carcerária masculina $(220,20 \%)$. No estado de Mato Grosso são 768 detentas, sendo que 57 se encontram na Cadeia Pública Feminina de município polo da região médio norte de Mato Grosso. ${ }^{(6)}$

Os motivos que levam as mulheres a cometerem crimes no Brasil são múltiplos e em sua maioria estão associados às relações íntimo-afetivas, como provas de amor ao companheiro(a), familiares ou amigos, situação econômica desfavorável, já que encontram no mundo do crime um caminho rápido e fácil para conseguirem recursos financeiros, além do maior reconhecimento perante os homens e respeito advindo das demais mulheres, representando uma necessidade de poder e status social como forma de satisfação pessoal. Sendo assim, esse grupo se torna ainda mais vulnerável ao encarceramento, coadjuvado pelas relações de poder homem-mulher e consequente exclusão dessa massa. ${ }^{(3,7)}$

Mediante tais constatações e havendo a necessidade de uma investigação atualizada do perfil da população carcerária feminina, tornou-se fundamental a discussão sobre essa realidade que diariamente as mulheres vivenciam ao encontrarem na criminalidade o caminho para a redução das desigualdades sociais e acesso aos bens e serviços das quais é privada. No entanto essa busca em sua maioria termina com o aprisionamento, que resulta no distanciamento de seus filhos, abandono do companheiro e familiares e culmina com maior exclusão social, após o processo de ressocialização. ${ }^{(8)}$

Neste cenário, objetivou-se apresentar o perfil de mulheres privadas de liberdade da Cadeia Pública Feminina do estado de Mato Grosso, no município da região médio norte de Mato Grosso.

\section{Material e Método}

Trata-se de um estudo transversal, com abordagem quantitativa. A pesquisa foi desenvolvida na Cadeia Pública Feminina de um município da região médio norte de Mato Grosso junto as 57 mulheres condenadas ou em regime provisório, correspondendo ao número total de detentas na instituição, sendo uma amostragem por conveniência.

Em 1978 houve a inauguração da unidade prisional onde atualmente funciona a Cadeia Pública Feminina, construída por uma ação conjunta em parceria com o Governo do Estado de Mato Grosso e o município de Tangará da Serra/MT. Funcionou inicialmente atendendo presos do sexo masculino, posteriormente, tornou-se misto, e assim permaneceu até 2009 quando o Centro de Detenção Masculino foi inaugurado, sendo os homens transferidos.

Atualmente atende apenas mulheres e tem capacidade para 58 reeducandas, distribuídas em oito celas. A unidade conta com 21 servidores para realização da segurança e recebe apoio dos servidores do setor da saúde do Centro de Detenção, a população atendida pertence aos mais variados municípios do estado e estados circunvizinhos.

A coleta de dados foi realizada no mês de outubro de 2016, através de entrevista em ambiente reservado, duração de trinta minutos para cada reeducanda e aplicação de formulário semiestruturado elaborado pelos pesquisadores, contendo perguntas abertas e fechadas que abordavam as variáveis relacionadas ao perfil sociodemográfico (idade, raçalcor, escolaridade, estado civil, profissão e renda), aspectos familiares (estrutura familiar, ter filhos e número, receber visita de familiares, receber visita íntima) antecedentes do aprisionamento (antecedentes criminais, tipo de crime que ocasionou a detenção, consumo de álcool e drogas, vivência de violência, residência anterior a detenção, tipo de residência, acesso á agua e esgoto, 
histórico de criminalidade e drogadição dos pais), vivências no aprisionamento (número de parceiras de cela e relacionamento) e perspectivas após liberdade (possibilidade de retorno ao crime, preconceito e perspectivas após a ressocialização).

Os dados foram sistematizados em planilhas eletrônicas em dupla digitação, posteriormente confrontados para busca de possíveis falhas na digitação. Após a completitude dos dados e construção do banco, o mesmo foi importado para o Statistical Package for the Social Sciences (SPSS) versão 20.0 para que as análises estatísticas fossem executadas. Foi realizado análise descritiva dos dados, e os resultados foram constituídos por gráficos e tabelas de distribuição de frequência absoluta e relativa.

$\mathrm{O}$ estudo integra o projeto de pesquisa matricial de coorte "Situação de Saúde de Trabalhadores e Internas de uma cadeia pública feminina de Mato Grosso", aprovado pelo Comitê de Ética em Pesquisa com seres humanos da Universidade do Estado de Mato Grosso, sob CAAE: 50417815.8.0000.5166 e parecer 1.457.621/2016. Todos os aspectos éticos em pesquisa que envolvem serem humanos foram atendidos de acordo com a Resolução CNS 466\2012. Ressalta-se que todas as mulheres foram informadas dos riscos e benefícios do estudo, além dos demais itens do TCLE que assinaram como pré-requisito para participar deste estudo.

\section{Resultados e Discussão}

Os dados coletados acerca da demografia das detentas (Tabela 1) evidenciaram mulheres jovens na faixa etária entre 18 a 31 anos $(56,1 \%)$. A raça/cor predominante foi a parda $(73,7 \%)$, referida por meio da autoafirmação durante entrevista e preenchimento do formulário. Essas informações coincidiram com a constatação demográfica do estudo realizado na delegacia do interior do Paraná sobre o perfil de detentas, que também retratou a prevalência de mulheres jovens ${ }^{(9)}$, e com os resultados da pesquisa realizada no Centro de Referência à Gestante Privada de Liberdade (CRGLP) de Vespasiano - MG, que verificou o alto índice da cor parda $(49,1 \%)$, seguida da cor branca e negra. ${ }^{(10)}$
Tabela 1 - Perfil socioeconômico das participantes. Município da região médio norte de Mato Grosso, Brasil. Outubro de 2016.

\begin{tabular}{|c|c|c|}
\hline $\begin{array}{l}\text { Idade (anos } \\
\text { completos) }\end{array}$ & Frequência & $\%$ \\
\hline $18-31$ & 32 & 56,2 \\
\hline $32-45$ & 18 & 31,6 \\
\hline $46-59$ & 7 & 12,3 \\
\hline Total & 57 & 100,0 \\
\hline \multicolumn{3}{|l|}{ Raça/cor } \\
\hline Branca & 7 & 12,3 \\
\hline Parda & 42 & 73,7 \\
\hline Negra & 7 & 12,3 \\
\hline Oriental & 1 & 1,8 \\
\hline Total & 57 & 100,0 \\
\hline \multicolumn{3}{|l|}{ Estado Civil } \\
\hline Solteira & 27 & 47,4 \\
\hline Casada & 3 & 5,3 \\
\hline União estável & 17 & 29,8 \\
\hline $\begin{array}{l}\text { Separada/ } \\
\text { divorciada }\end{array}$ & 7 & 12,3 \\
\hline Viúva & 3 & 5,3 \\
\hline Total & 57 & 100,0 \\
\hline \multicolumn{3}{|l|}{ Número de filhos } \\
\hline 0 & 10 & 17,5 \\
\hline 1 & 10 & 17,5 \\
\hline 2 & 14 & 24,6 \\
\hline 3 & 10 & 17,5 \\
\hline 4 ou mais & 13 & 22,9 \\
\hline Total & 57 & 100,0 \\
\hline
\end{tabular}

\begin{tabular}{ccc}
\hline Escolaridade & & \\
\hline Não alfabetizada & 1 & 1,8 \\
Ensino & 32 & 56,2 \\
fundamental & 21 & 36,8 \\
Ensino médio & 3 & 5,3 \\
Ensino superior & 57 & 100,0 \\
Total & & \\
\hline Profissão & 22 & 38,6 \\
\hline Do lar & 6 & 10,5 \\
Vendedora & 4 & 7 \\
Empregada & 3 & 5,3 \\
doméstica & 3 & 5,3 \\
Traficante & 3 & 5,3 \\
Manicure & 3 & 5,3 \\
Cabeleireira & 2 & 3,6 \\
Cozinheira & 2 & 3,6 \\
Autônoma & 2 & 3,6 \\
Garota de & programa & 12,3 \\
Servente geral & 2 & 100,0 \\
Outros & 57 & \\
Total & &
\end{tabular}


$\mathrm{Na}$ pesquisa nacional sobre ex-presidiárias assistidas pelo Programa de Inclusão Social de Egressos do Sistema Prisional (PrEsp) também encontraram resultados parecidos com um índice superior a $40 \%$ de inscritas com faixa etária até 30 anos e 53,8\% de mulheres negras e pardas.(11) Nos estudos internacionais também foram compostas por jovens, por exemplo, na Colômbia $41,8 \%$ possuíam faixa etária de 18 a 29 anos, bem como na Europa, onde a variabilidade de idades foi de 18 a 30 anos. $(2,12)$

A maior parcela das detentas eram solteiras $(47,4 \%)$ e em relação ao número de filhos, 59,6\% possuíam até 3 filhos, sendo que 14 delas tinham dois filhos. Observou-se que $17,5 \%$ não tinham filhos, que possivelmente está associada ao aprisionamento de muitas mulheres jovens e solteiras. Apenas $1,8 \%$ das mulheres encarceradas possuíam mais de 10 filhos, o que evidencia a diminuição da taxa de fecundidade nacional (2,4 para 1,9 filhos em média)(13) coincidindo com dados descritos anteriormente.

No entanto os prejuízos socioeconômicos do aprisionamento de mulheres são maiores uma vez que a vivência dessa realidade por seus filhos pode contribuir para o aumento da vulnerabilidade dos mesmos ao crime e consequente perpetuação do encarceramento pelas gerações futuras.(14-16)

O grau de escolaridade predominante das detentas foi o ensino fundamental $(56,1 \%)$, conforme verificado também entre detentas americanas.(3) Observou-se que somente $5,3 \%$ delas possuíam ensino superior, o que remete à escassa qualificação profissional como um potencial fator que possa ter contribuído para a escolha da criminalidade, correspondendo a um meio fácil e rápido de subsistência. A baixa escolaridade também foi descrita nos presídios do Paraná, onde $65,5 \%$ das detentas possuíam ensino fundamental incompleto ou grau de instrução inferior ao ensino fundamental.

Dentre as profissões referidas pelas detentas houve predomínio de mulheres que não são remuneradas pelo trabalho doméstico, porém consideram como a profissão que desenvolviam antes da prisão "do larldona de casa" $(38,6 \%)$, seguida por vendedora (10,5\%). Na Bahia (45,4\%) e em São Paulo $(21,1 \%)$ a profissão que mais se destacou nesse âmbito foi a doméstica, estas que possuem remuneração por atuar nos cuidados do lar de outras famílias,(9) que correspondeu a $4^{\circ}$ profissão mais comum neste estudo. Outras pesquisas evidenciaram que as profissões informadas pelas detentas são atividades de baixa renda, como vendedora, manicure, do lar, cozinheira e cabeleireira, o que sugere que há uma predominância das mesmas atividades profissionais na população carcerária feminina brasileira.(17)

Dessa forma, todos esses fatores são condicionantes para o envolvimento com o crime, pois a jovialidade associada à baixa formação escolar, consequentemente, a ausência de profissão ou exercício de atividades com baixa remuneração, resultam na complementação de atividades ilegais(17) como o tráfico de drogas, roubo e latrocínio. Exemplo disso, as entrevistadas relataram a necessidade de terem fontes de renda secundárias para o mantimento de suas casas e famílias.

Entre os principais crimes cometidos (Figura 1), a maioria foi por tráfico de drogas $(54,4 \%)$ seguido por homicídio $(12,3 \%)$ e roubo $(10,5 \%)$. Esses resultados foram semelhantes com a pesquisa realizada no Paraná, onde $77 \%$ das entrevistadas informaram terem sido condenadas por tráfico de drogas e $23 \%$ por furto e roubo, e no estado de Goiás onde 89,6\% das condenações também foram por esse primeiro motivo. Em estudos internacionais realizados nos Estados Unidos e na Europa, as prisões femininas foram associadas aos crimes de drogas e contra a propriedade.(3)

Figura 1 - Principais motivos de detenção. Município da região médio norte de Mato Grosso, Brasil. Outubro de 2016.

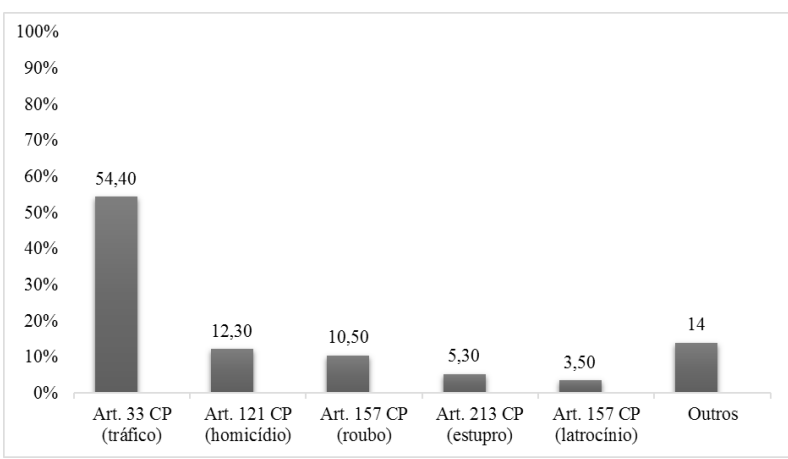

O consumo e vício em drogas, em muitas ocasiões, são provenientes da extrema pobreza, onde o estado de fome é suprido por meio da letargia causada principalmente pela bebida alcoólica ou pela "cola de sapateiro".(18) Grande parcela das detentas sentenciadas por tráfico de drogas afirmaram fazer uso 
de drogas lícitas e ilícitas. Justificaram o crime como forma de sustentar o próprio vício.

Existe uma combinação entre fatores socioeconômicos e afetivos, representada pela participação da mulher na criminalidade em decorrência do parceiro, demonstrando apoio, igualdade de gênero e/ou desmistificando a imagem da mulher construída pela sociedade. Além disso, se enquadram os homicídios em defesa do casamento ou por questões de sobrevivência que estão relacionados com o aspecto financeiro, enfatizado por meio da baixa escolaridade, que leva a trabalhos desvalorizados, habitação em regiões periféricas, onde a qualidade de vida é minimamente presente e o preconceito racial constante. Assim, a escolha do tráfico serve como um meio de obtenção de recursos, visando principalmente, o sustento familiar.(17,19)

Segundo levantamento nacional de informações penitenciárias (Infopen) os principais crimes atribuídos aos encarcerados brasileiros correspondem aos crimes contra o patrimônio, pessoas e drogas, representando $87 \%$ do total de aprisionamentos. O tráfico de entorpecentes e roubo equivalem a mais de $50 \%$ das sentenças, sendo responsáveis pelo aumento do número de reclusões no país.(20) Em 2016, esse índice alcançou $68 \%$ sendo que o envolvimento da mulher ocorreu como coadjuvante no transporte das drogas e comércio, onde a maioria também era usuária. Desse modo, ressalta-se a carência e relevância da efetividade das políticas de combate às drogas, bem como dos programas para recuperação de viciados.

O tempo de detenção das reeducandas em estudo, em sua maioria $(82,5 \%)$ foi por um curto período $(0$ a 2 anos), sendo que 59,6\% haviam sido presas pela primeira vez (Tabela 2). As demais detentas já haviam sido detidas anteriormente pelos crimes de tráfico de drogas, homicídio, roubo, porte ilegal de arma, furto e formação de quadrilha. Infrações essas que se repetiram no envolvimento com a criminalidade.
Tabela 2 - Tempo de detenção, antecedentes criminais e motivo do encarceramento. Município da região médio norte de Mato Grosso, Brasil. Outubro de 2016.

\begin{tabular}{ccc}
\hline $\begin{array}{c}\text { Tempo de } \\
\text { detenção }\end{array}$ & Frequência & \% \\
\hline $0-2^{\mathrm{a}}$ & 47 & 82,5 \\
$2 \mathrm{a} 1 \mathrm{~d}-4^{\mathrm{a}}$ & 8 & 14 \\
$4 \mathrm{a} 1 \mathrm{~d}-6^{\mathrm{a}}$ & 2 & 3,5 \\
\hline $\begin{array}{c}\text { Antecedentes } \\
\text { criminais }\end{array}$ & & \\
\hline Não possuem & 34 & 59,6 \\
Possuem & 23 & 40,4 \\
\hline $\begin{array}{c}\text { Motivo do } \\
\text { encarceramento }\end{array}$ & & \\
\hline Art. 33 CP & 11 & 19,3 \\
Art. $121 \mathrm{CP}$ & 4 & 7,1 \\
Art. $157 \mathrm{CP}$ & 2 & 3,6 \\
Art. $19 \mathrm{CP}$ & 2 & 3,6 \\
Art. $155 \mathrm{CP}$ & 2 & 3,5 \\
Art. $288 \mathrm{CP}$ & 2 & 3,3 \\
\hline
\end{tabular}

Os antecedentes da detenção demonstram que $78,9 \%$ das mulheres moravam com a família; $15,8 \%$ sozinhas e $5,3 \%$ com amigos, sendo que a maioria $(54,4 \%)$ possuía moradia própria com água encanada e fossa séptica como meio de descarte dos dejetos. Assim como as detentas, o grau de escolaridade das mães mais apontado foi ensino fundamental incompleto e dos pais, não alfabetizados, remetendo a um desafio de ordem global, já que um terço da população mundial é analfabeta. Nos países em desenvolvimento esse índice chega a atingir metade dos habitantes, esse fator impede a plena cidadania da população, incluindo o direito à democracia, o que contribui, consequentemente, para a exclusão social e pobreza.(21)

Ao analisar o âmbito familiar, ela possui a capacidade de sobrevivência e adaptação, o que gera variadas composições humanísticas e padrões de relacionamento. Formada para a sociedade, a família impacta diretamente no desenvolvimento e maturidade emocional do indivíduo.(22,23) Esse papel se perpetua desde a antiguidade, onde ela é reconhecida pela influência a qual exerce sobre a vida das pessoas bem como na interação com o meio em que vive, que são determinantes para os aspectos quanto à 
personalidade e comportamentos. $(23,24)$ Em suma, é responsável pelo princípio da socialização de crianças e adolescentes, a partir da utilização de regras e limites nos relacionamentos com diferentes gerações que viabiliza a adaptação individual na convivência com a coletividade. $(22,25)$

Essa instituição também exerce importante influência na vida criminal das detentas, pois o contato com a criminalidade, por vezes, se inicia em âmbito doméstico através de familiares e/ou pessoas próximas. Em outras situações, o crime é praticado juntamente com o familiar, principalmente com o parceiro (a), que relaciona o apoio do companheiro em $42,1 \%$ das detenções. Há uma relação diretamente proporcional nesse contexto, em que a variável estabilidade relacional familiar influencia a probabilidade ao envolvimento no crime. Além disso, o ambiente doméstico pode contribuir com a criminalidade, pois, rotineiramente, crimes como tráfico de drogas, ocorrem no domicílio do indivíduo.(26)

Apesar de 52,6\% dos pais não consumirem álcool ou outras drogas psicoativas, $47,4 \%$ seguem esse estilo de vida, sendo esta, uma condição agravante da violência, já que $54,4 \%$ das detentas foram violentadas antes de serem detidas. Os resultados dos estudos nacionais concluíram que $32,2 \%$ das violências cometidas foram físicas, 31,8\% psicológicas e 3,8\% sexuais, partindo dos parceiros, genitores, pais adotivos e demais familiares.(27)

Apesar da recidiva criminal após o cumprimento da pena, o sujeito é privado de liberdade devido ao novo envolvimento com o crime. Essa situação é considerada como um fator agravante do tempo de detenção por meio do artigo 61 do Código Penal, por dificultar a aquisição de benefícios como impedimento da concessão de suspensão condicional de cumprimento e diminuição da pena. Isso faz com que aumente o período de pretensão executória bem como a interrupção da prescrição.(28) Tal fato foi observado no contexto da localidade do estudo e se concluiu que isso não intimida uma parcela das detentas (12,3\%) que afirmou nova possibilidade de cometerem outro crime.

A escolha do envolvimento do sexo feminino na criminalidade e sua participação repetida no crime consistem na ideia de que a mulher é considerada menos suspeita, devido a uma cultura machista que designa maior propensão ao homem. Além disso, as revistas costumam ser realizadas por policiais do sexo masculino, sendo realizada em mulheres somente nos casos de suspeita fundamentada, ausência de policial do sexo feminino ou quando não houver constrangimento por parte da mulher abordada.(28) Já foi comprovado que o cárcere privado não evita a recorrência dos crimes, desse modo, é necessário buscar alternativas que permitam ao autor do delito assumir a responsabilidade por sua ação e repará-la adequadamente.(29)

O cenário de violência na detenção pode ser perpetuado, visto que as detentas podem sofrer violência por parte de outras detentas e/ou de policiais e agentes penitenciários, que abusam da autoridade a eles delegada e espancam ou agem com extrema brutalidade. A impunidade por esse tipo de comportamento, na maioria das vezes, é analisada de forma equivocada quando avaliada na perspectiva de reeducação, quando na verdade, ocasiona ainda mais revolta e diminui a perspectiva de uma futura ressocialização.(30)

Durante o estudo foi identificado que $87,8 \%$ das detentas dividem a cela com 6 a 15 mulheres, sendo que $42,1 \%$ afirmaram não serem próximas de nenhuma colega de confinamento. Essa realidade pode resultar em duas situações: risco de infecções pelo aglomerado de pessoas e qualidade do ambiente, além de consequências comportamentais negativas decorrentes do contato prolongado com diversos tipos de experiências ligados ao crime.(31-32)

A necessidade da redução populacional das penitenciárias é notável, porém distante da realidade, considerando as lotações e superlotações das celas. O artigo 88 da LEP preconiza que o condenado seja alojado individualmente, com disponibilidade de dormitório, sanitário e lavatório, contudo, há controvérsia pela condição atual nos presídios. Isso pode levar a consequências negativas como as frágeis relações interpessoais, tanto com as colegas de cárcere como com a equipe de segurança, descontrole das atividades profissionais e estímulo à violência, defraudando o caráter de ressocialização das penitenciárias.(8)

Esse cenário estimula o surgimento e desenvolvimento de doenças mentais em encarcerados, visto que o ambiente penitenciário já perturba ou impossibilita o funcionamento desses mecanismos devido ao fato de haver uma grande mudança em relação ao comportamento do indivíduo, convívio social e familiar, onde a monotonia se destaca consideravelmente.(8)

$\mathrm{O}$ ambiente prisional abrange elevada prevalência de transtornos mentais, ultrapassando os índices da 
população em geral, o que resulta em comportamentos autodestrutivos por parte dos encarcerados. Estudo brasileiro demonstra que as detentas são as mais predispostas a serem acometidas por doenças mentais, necessitando de acompanhamento psicológico e tratamento com medicação psicotrópica, realizados pela equipe multidisciplinar em saúde. Muitas vezes se observa a indisponibilidade dessas medicações no âmbito penitenciário, apesar de existir legislações que abordem os direitos dos indivíduos em situação prisional.(33)

Como um meio de amenizar essa mudança de vida e promover maior bem-estar à detenta, além de assegurar a recreação e a realização das atividades profissionais, artísticas e desportivas, conforme prevista na LEP, são oferecidos, baseado no tipo de execução da pena, artesanato, aulas de educação física, culinária, pintura, cursos, horticultura, serviços gerais e crochê. Essas atividades são um meio de aquisição de recursos, pois a partir da venda dos produtos manufaturados, a renda é revertida para a compra de produtos de higiene e beleza, alimentos, medicamentos e novos materiais para a manutenção do ciclo econômico, além de outros produtos ausentes durante visitas.(4)

Estudo realizado em Sergipe também aponta atividades laborais, educativas e desportivas realizadas por aprisionados, como gincanas culturais em datas comemorativas, mutirões de beleza, palestras, quadrilhas, teatros, comemorações natalinas, programas de alfabetização, educação de jovens e adultos (EJA), além de oficinas de corte e costura, artesanato, cursos de cabeleireiro e manicure como forma de geração de renda, futebol e caminhada. (34) Todas essas atividades possibilitam a redução do tempo de encarceramento, além de constituírem uma fonte de renda extra e de interação social.

Foi contabilizado que $50,9 \%$ das detentas recebiam visita, sendo principalmente dos filhos e da mãe. Em relação à visita íntima, 94,7\% disseram não receber, sendo justificado pela ausência de parceiros (grande quantitativo de mulheres solteiras), pela detenção do companheiro por envolvimento no crime, constrangimentos e/ou relações homossexuais com as demais detentas. Estudo no estado de São Paulo afirma que mesmo após a legalização do direito de visita íntima, a adesão foi baixa.(9)

O objetivo da pena não é apenas a ressocialização, porém se constitui como uma das finalidades. As disciplinas penais não possuem capacidade, de isoladamente, promoverem total ressocialização dos reclusos. Portanto, há a necessidade da integração com programas na área e formas de controle social, onde os principais responsáveis são o Estado e a sociedade juntamente com demais órgãos, como escola, igreja e família.(30)

Trata-se de um processo complexo, permeado de desafios para o retorno de uma vida longe da criminalidade. O preconceito foi um dos itens $(77,2 \%)$ mais citados pelas detentas como a maior limitação a que podem estar submetidas ao longo da vida. Geralmente é caracterizado pelo estigma de ex-presidiária, seguida da desvalorização pessoal, o que dificulta a sua reinserção familiar, social e profissional, contribuindo para o aumento da violência e reincidência em cerca de $70 \%$ dos casos, conforme presidente do Supremo Tribunal Federal e do Conselho Nacional de Justiça.(35)

A prisão é denotada apenas como punitiva, margeiase da questão da integração social preconizada no artigo primeiro da LEP. É comum ao retornarem para o meio social, depararem-se com relacionamentos familiares desgastados, relações sociais pautadas no preconceito e dificuldade de inserção no mercado de trabalho. Tudo isso reforça a ideia de que o encarceramento não assume papel integral no desenvolvimento humano, colaborando com o prejuízo ao ex-presidiário.(36)

Assim, a ausência e/ou fragilidade dos programas que assistam às particularidades dessa população após liberdade, a falta de confiança e o preconceito são consideradas como barreiras que contribuem para a reincidência criminal e manutenção do ciclo de criminalidade. A superação dessa situação deve ser realizada com a soma de esforços por parte dos diversos órgãos e investimento financeiro a fim de promover a inclusão social das ex-detentas, minimizando a violência e a expansão de sistemas prisionais.(37)

O governo tem se esforçado para integrar essas pessoas à sociedade por meio da LEP e de Projetos de lei mais recentes que incentivam as empresas a contratarem ex-detentos, atribuindo-lhes dedução dos encargos sociais. $(1,38)$ O Conselho Nacional de Justiça (CNJ) também tem se empenhado nessa tarefa com o projeto Começar de Novo que tem como objetivo promover ações para ressocialização de presos e egressos do sistema prisional, com a criação de oportunidades de trabalho e de reeducação social e profissional.(39)

Esses incentivos já começaram a surtir efeito, projetos e ações desenvolvidas no município de Maringá-PR e em Brasília mostraram a possibilidade 
efetiva do processo de ressocialização através da contratação de egressos do sistema carcerário.(35) Ações como essas constituem formas imprescindíveis de reinserção social de ex-detentas, dado o reconhecimento de que a sociedade necessita acolher essa população, seja como um meio de propiciar maior controle social ou diminuir a criminalidade que possa estar associada à carência de oportunidades pós detenção.

\section{Conclusão}

O perfil socioeconômico destacou o predomínio de reeducandas que se autodeclaram pardas $(73,7 \%)$, com faixa etária entre 18 e 31 anos (56,2\%), ensino fundamental incompleto $(56,2 \%)$, donas de casa $(38,6 \%)$, solteiras $(47,4 \%)$, com até 4 filhos $(82,5 \%)$, detidas pelo crime de tráfico de drogas $(54,4 \%)$ e com período de reclusão de até dois anos $(82,5 \%)$.

Os aspectos familiares e antecedentes do aprisionamento apontam que $47,4 \%$ dos pais das reeducandas fazem uso de álcool e drogas, agiram com violência com $54,4 \%$ das detentas, ainda assim $78,9 \%$ das mulheres moravam com a família, a maioria $(54,4 \%)$ em moradia própria, com água encanada e fossa séptica. O tempo de detenção é curto, com menos de anos de vivencia no cárcere $(82,5 \%)$ e 59,6\% foram presas pela primeira vez, como causa principal o tráfico de drogas $(54,4 \%)$. A vivência do aprisionamento revela que $87,8 \%$ das detentas dividem a cela com 6 a 15 mulheres, $42,1 \%$ não possuem boa relação com colega de confinamento, assim as perspectivas após o aprisionamento apontam que preconceito pode limitar sua reinserção social e profissional $(77,2 \%)$, o que pode justificar que $12,3 \%$ afirmam a possibilidade de cometerem outro crime após terem acesso a liberdade reduzindo as possibilidades de acesso a saúde e qualidade de vida.

A necessidade de conhecimento dessa realidade se torna importante devido ao crescimento da população carcerária, sobretudo a feminina. A partir dessas informações há possibilidade de desenvolver medidas de prevenção da criminalidade, incluindo políticas de reinserção do ex-presidiário e incentivo ao controle social, além da adoção de medidas para evitar a reincidência ao crime. Como formas de promover essa reinserção, sugere-se a reestruturação das políticas públicas, além de estratégias de abordagem familiar buscando reduzir o abandono e perda do contato com os filhos durante o aprisionamento e somente assim será possível a redução dessa população, do preconceito, da violência gerados pelo estigma do cárcere e das consequências na saúde dessas mulheres.

A partir dos resultados, percebe-se como limitação o estudo ter abordagem local, o que inviabiliza extrapolar e comparar para outras regiões e assim comparar as influências do cárcere na saúde. Nesse sentido, é fundamental realização de mais pesquisas que abordem essa população, buscando reduzir as vulnerabilidade e iniquidades a que estão expostas e assim minimizar os riscos para sua saúde e qualidade de vida.

\section{Referências}

1 Brasil. Lei n. 7.210 de 11 de julho de 1984. Institui a Lei de Execução Penal. Diário Oficial da União 13 jul; 1984.

2 García LA, Domínguez AIC. Realidad penitenciaria en Colombia: la necessidad de una nueva política criminal. Rev Crim. 2016 May-Aug;58(2):175-95.

3 Mignon S. Health issues of incarcerated women in the United States. Cien Saúde Colet. 2016 July;21(7):2051-60. doi: 10.1590/141381232015217.05302016

4 Alves ACBB. Privatização dos presídios brasileiros e impactos sociais. Cienc. Hum. Soc. Unit. 2015;2(3):237-56.

5 Arruda AG, Oss LES, Maciel PX. Os presídios no Brasil: o histórico da pena e a comparação entre o sistema carcerário tradicional e o método APAC. In: Anais do $3^{\circ}$ Congresso de Pesquisa e Extensão da Faculdade da Serra Gaúcha; 2015; Porto Alegre: FSG; 2015.

6 Ministério da Justiça (BR). Departamento Penitenciário Nacional. Levantamento Nacional de Informações Penitenciárias INFOPEN MULHERES. [Internet] 2014 [citado $2017 \mathrm{fev} 23$ ]. Disponível em: https://www.justica.gov.br/noticias/ estudo-traca-perfil-da-populacao-penitenciariafeminina-no-brasil/relatorio-infopen-mulheres.pdf 
7 Bianchini A, Barroso MG. Mulheres, tráfico de drogas e sua maior vulnerabilidade: série mulher e crime [Internet]. 2012 [citado 2017 jan 6]. Disponível em: http://www.mp.go.gov.br/ portalweb/hp/41/docs/artigo_-_mulheres,_trafico_ de_drogas_e_sua_maior_vulnerabilidade.pdf

8 Azevedo AHC, Levy CHS, Almo MPS, Pasoline WF, Souza ZS, Cavalli K. Sistema prisional brasileiro. Rev Cient UNESC. 2015;13(16):42-60.

9 Agnolo CMD, Belentani LM, Jardim APS, Carvalho MDB, Pelloso SM. Perfil de mulheres privadas de liberdade no interior do Paraná. Rev. Baiana Saúde Pública. 2013;37(4):820-34.

10 Ferrari IF, Machado MNM. Perfis de mães detentas convivendo com seus filhos. Pesqui Prát Psicossociais. 2014 dez;9(2):173-83.

11 Sá PP. Dossiê: as mulheres e o sistema penal. Curitiba: OABPR; 2015.

12 España EG, Muñoz JB, Conde AA, España EG, Ripollés JLD. Realidad y política penitenciarias. Valencia: Tirant lo Blanch; 2012.

13 Berquó ES, Cavenaghi SM. Tendências dos diferenciais educacionais e econômicos da fecundidade no Brasil entre 2000 e 2010. In: Anais do $19^{\circ}$ Encontro Nacional de Estudos Populacionais; 2014; São Pedro; 2014.

14 Assis SG. Traçando caminhos em uma sociedade violenta: a vida de jovens infratores e de seus irmãos não-infratores. Rio de Janeiro: FIOCRUZ; 1999.

15 Kristensen P, Weisaeth L, Heir T. Bereavement and mental health after sudden and violent losses: a review. Psychiatry. 2012;75(1):76-97. doi:10.1521/ psyc.2012.75.1.76.

16 Lisboa AV, Féres-Carneiro T. Acontecimentos significativos na história geracional e sua relação com somatizações na família. Psic. Teor. e Pesq. 2015 jan-mar;31(1):65-72. doi: 10.1590/010237722015011182065072

17 Camargo JP, Rutkoswki FP, Borba EO, Neves EB. O perfil das detentas HIV positivo de uma penitenciária estadual do Paraná, Brasil. J. Health Sci Inst. 2012;30(4):369-76
18 Neis C. Fatores da criminalidade: um estudo sobre a influência dos fatores sociais na prática das infrações penais. Biguaçu: EdUNIVALI; 2008.

19 Souza C, Santos HA. Mulheres no cárcere: um estudo sobre o perfil sócioeconômico das apenadas de uma unidade prisional do Rio Grande do Norte - Brasil. In: $2^{a}$ Jornada de Género y diversidad sexual; 2016; La Plata; 2016.

20 Ministério da Justiça (BR). Departamento Penitenciário Nacional. Levantamento Nacional de Informações Penitenciárias - INFOPEN [Internet] 2014 [citado 2017 fev 23]. Disponível em: http:// www.justica.gov.br/seus-direitos/politica-penal/ documentos/infopen_dez14.pdf

21 Diniz GM, Machado DQ, Moura HJ. Políticas públicas de combate ao analfabetismo no Brasil: uma investigação sobre a atuação do Programa Brasil Alfabetizado em municípios do Ceará. Rev. Adm. Pública. 2014 may-june;48(3):641-66. doi: 10.1590/0034-76121514.

22 Oliveira D, Siqueira AC, Dell'Aglio DD, Lopes RCS. Impacto das configurações familiares no desenvolvimento de crianças e adolescentes: uma revisão da produção científica. Interação Psicol. 2008;12(1):87-98. doi: 10.5380/psi.v12i1.9172

23 Nascimento AIC, Teodoro MLF, Carvalho MJC. A influência das relações familiares no comportamento infrator de adolescentes. [Internet]. 2012 [citado $2017 \mathrm{fev}$ 23]. Disponível em: http://www.unicap.br/jubra/wp-content/ uploads/2012/10/TRABALHO-147.pdf

24 Biasoli-Alves ZMM. Pesquisando e intervindo com famílias de camadas diversificadas. Florianópolis: Papa-livro; 2004.

25 Schenker M, Minayo MCS. A implicação da família no uso abusivo de drogas: uma revisão crítica. Ciênc. saúde Col. 2003;8(1):707-17. doi: 10.1590/ S1413-81232003000100022

26 Guimarães JLC. Motivações do crime segundo o criminoso: condições econômicas, interação social e herança familiar. Rev Bras Segur Pública. 2014;8(1):112-31. 
27 Ferreira VP, Silva MA, Noronha NC, Falbo NGH, Chaves CV, Bello RP. Prevalência e fatores associados à violência sofrida em mulheres encarceradas por tráfico de drogas no Estado de Pernambuco, Brasil: um estudo transversal. Ciênc Saúde Colet. 2014;19(7):2255-64.

28 Martins LM, Santana IJ. O encarceramento feminino no estado de Mato Grosso do Sul e a reincidência criminal. Em Tempo; 2015;14:259-76.

29 Instituto de Pesquisa Econômica Aplicada. Reincidênciacriminal no Brasil: relatóriodepesquisa [Internet]. Rio de Janeiro: IPEA; 2015 [citado 2017 ago 3]. Disponível em: http://www.cnj.jus.br/files/ conteudo/destaques/arquivo/2015/07/572bba3853 57003379ffeb4c9aa1 f0d9.pdf

30 Santos G. Ressocialização do preso frente ao sistema penitenciário brasileiro. Ijuí: EdUNIJUI; 2015

31 Silva EF, Ribeiro ER. Atenção à saúde da mulher em situação prisional. Rev Saúde Desenvolv. 4. ed; 2013 jul-dez;4(2):161-72.

32 Ribeiro SG, Lessa PRA, Monte AS, Bernardo EBR, Nicolau AIO, Pinheiro AB. Perfil gineco-obstétrico de mulheres encarceradas no estado do Ceará. Texto Contexto - Enferm. 2013 jan-mar; 22(1):1321. doi: $10.1590 / \mathrm{S} 0104-07072013000100002$

33 Fochi MCS, Silva ARC, Lopes MHBM. Pré-natal em unidade básica de saúde a gestantes em situação prisional. Rev Rene. 2014;15(2):371-7.

34 Andrade FS. Pela cortina do desvio: a trajetória de mulheres presas do presídio feminino de Nossa Senhora do Socorro - SE. São Cristóvão: EdUFS; 2015.

35 Vasconcelos FPS. Ressocialização do preso e do egresso: fundamentos para a participação da sociedade à luz de aspectos social, religioso, filosófico e jurídico. Brasília: EdUniCEUB; 2014.

36 Gonçalves PT, Ribeiro DF, Ventura CAA. O percurso de vida de ex-presidiários: reflexões sobre prisão e desenvolvimento humano e social. Rev. Perspect Desenvolv. 2015;3(4):1-33.
37 Comissão de Formação Teórica e Prática do PrEsp (MG). O egresso do sistema prisional: do estigma à inclusão social [Internet]. Belo Horizonte: Insituto Elo; 2013 [citado 2017 ago 3]. Disponível em: https://institutoelo.org.br/site/files/publications/62 49f589266779f9bd30d6a403db544f.pdf

38 Senado Federal (BR). Projeto de Lei do Senado ${ }^{\circ}$ 70, de 2010. Dispõe sobre a dedução dos encargos sociais devidos pelas pessoas jurídicas tributadas com base no lucro real, em caso de contratação de egressos do sistema prisional, e dá outras providências. Brasília; 2015.

39 Conselho Nacional de Justiça (BR). Portal de Oportunidades: Começar de Novo [Internet]. Brasília; 2017 [citado 2017 ago 3]. Disponível em: http://www.cnj.jus.br/sistemas/sistema-carcerarioe-execucao-penal/20550-portal-de-oportunidadescomecar-de-novo 